\title{
El problema de la historia en la teología de Gustavo Gutiérrez
}

\author{
Antonio González F. \\ Centro de Reflexión Teológica, \\ San Salvador, El Salvador.
}

\section{Introducción}

El tema de la historia constituye uno de los objetos preferidos de las críticas que los télogos latinoamericanos han recibido, tanto por parte de la autoridad magisterial como de otros teólogos europeos. A la teología de la liberación se le achaca una concepción ingenua del devenir histórico, caracterizada por el determinismo y el mecanicismo, que hundirían sus raices en la filosofia de la historia de Hegel y de Marx. Blanco de estos ataques ha sido, entre otros, la concepción de la historia expuesta en el conocido libro de Gustavo Gutiérrez Teologia de la liberación. Perspectivas. ${ }^{1}$ Evidentemente, esta obra posee un valor simbólico por constituir uno de los primeros esbozos de la nueva teologia latinoamericana a la que, en cierto modo, ha "bautizado." Por esto mismo, la descalificación de este libro, por mucho que éste ya no represente total y plenamente el estado actual de la reflexión de su autor, adquiere también alcances mayores que la discusión de una u otra tesis en él contenidas.

En concreto, la visión de la historia expuesta en su teología de la liberación ha sido acusada por algunos críticos de no ser más que una versión teologizante del proyecto filosofico de la ilustración "desde Saint-Simon hasta Bloch," que se caracterizaría por unir precipitadamente la teoria política a la metafísica. Además, lo propio de la ilustración sería un enfoque mecanicista, "fisicalista" de la metafísica. De este modo, la realidad en general y la historia en concreto no serían más que un ingente organismo, una máquina donde la libertad humana no tendría ningún lugar. Esta maquinaria histórica sería la 
encargada de producir al "hombre nuevo" con la eficacia y la irreversibilidad de un engranaje. Evidentemente, una concepción semejante entraría en una insoslayable contradicción con la fe cristiana, pues negaria la libertad y la responsabilidad del ser humano y, con ello, la posibilidad de un encuentro con Dios en la historia. Sin poner totalmente en tela de juicio la fe personal del téblogo (!), esta su primera obra merecería según alguno de sus críticos una tajante desaprobación. ${ }^{2}$

Desde una perspectiva más cordial y moderada, otros té́logos europeos han formulado críticas semejantes a la primera obra de Gutiérrez. Según algunos, el té́logo latinoamericano no habria alcanzado todavía la madurez "post-moderna" de las más recientes reflexiones de la teología europea. Gustavo Gutiérrez se seguiría moviendo, como otros muchos télogos clásicos alemanes (Rahner y Pannenberg, por ejemplo), dentro de la vision ilustrada ("moderna") del devenir histórico, caracterizada por presuponer la unidad universal de la historia humana. Esta única historia de la humanidad estaría dotada de un movimiento continuo de avance y de progreso, y ella misma sería el escenario de la historia de la salvación. No habría dos historias separadas, sino que la historia de la salvación, tal como la entiende la fe cristiana, acontecería en este mismo proceso ascendente y evolutivo llamado "historia universal," donde el género humano alcanzaria, a través de fases progresivas, mayores cotas de razón y de libertad. Ahora bien, según esta critica habria una diferencia importante entre las teologías de la historia de Rahner y de Pannenberg, por una parte, y la de Gustavo Gutiérrez, por otra. Para los primeros "los análisis profanos de la historia universal no pueden mostrarnos los caminos concretos de la salvación histórica en un momento dado." Para la teología de la liberación, por el contrario, la convocación cristiana a la esperanza se concretaría simplemente mediante los "análisis de la dialéctica socioeconómica del avance histórico."

Estas criticas, a pesar de la diversidad enorme de su origen y de sus presupuestos, coinciden en caracterizar la reflexión teológica sobre la historia contenida en el libro de Gutiérrez (Teologla de la liberación) con dos rasgos fundamentales: por una parte, el télogo peruano habría asumido acríticamente el modelo socioevolutivo de la ilustración y, por otra, Gutiérrez habría identificado precipitadamente el progreso socioeconómico con el desarrollo de la salvación (con la creación del "hombre nuevo"), mientras que la teología europea habría sido mucho más cuidadosa en este punto. 
Estos dos reproches fundamentales determinan el contenido de este trabajo: por una parte, habrá que ver en qué consiste exactamente la concepción ilustrada o moderna de la historia, pues no siempre que se habla de "libertad," "emancipacion," etc., se está diciendo con ello lo mismo que han dicho los ilustrados europeos de los siglos XVII-XDX Por ello, es menester considerar primero los rasgos generales de su visión de la historia para, después, ver si realmente coinciden con lo que Gutiérrez propone (sobre todo en Teologia de la liberación, que es el objeto favorito de las criticas). Por otra parte, será de suma utilidad para nuestro propósito considerar también cuál es la recepción que la teología europea actual hace de las reflexiones ilustradas sobre la historia (desde Kant hasta Marx), para asf entender mejor en qué consiste la originalidad de la concepción de la historia esbozada por la teología latinoamericana. Dados los límites de este trabajo, nos centraremos para ello en los trabajos de Karl Rahner sobre la historia, en cuanto exponente cualificado de la teología europea de este siglo.

\section{La concepción ilustrada de la historia}

Puede decirse que el interés principal de la reflexión de los filosofos ilustrados sobre la historia consiste en preguntarse por las condiciones de posibilidad de una real emancipación de los hombres respecto a la situación de inmadurez y de sometimiento en la que éstos se hallan. Si atendemos al origen de la reflexión sociopolítica de tres de los grandes filósofos ilustrados de la historia (Kant, Hegel, Marx) tal como se halla expuesta en sus respectivos escritos de juventud, ${ }^{6}$ encontramos en todos ellos el interés fundamental de que los hombres dejen de ser victimas de la historia que ellos mismos hacen para convertirse en sus verdaderos sujetos. Deben dejar atrás, como dice Kant, su "minoría de edad culpable" y tomar asf las riendas de su propia historia. Esta liberación tiene dos dimensiones. Por una parte, la humanidad ha de emanciparse del yugo de la naturaleza (enfermedades, catástrofes naturales, etc.); y, por otro lado, del yugo que unos hombres imponen a otros en el mundo de la economía y de la política (esclavitud, sometimiento, explotación). Liberación significa entonces "auto-liberación;" dominio racional de la historia por sus auténticos sujetos, para que deje de ser historia de la opresión y se convierta en historia de la libertad. La filosofía, la difusión pública de la ilustración, el conocimiento científico de la realidad, tienen evidentemente en este proceso una función fundamental: contribuir a la concientización de la humanidad sobre las causas de su so- 
metimiento (distintas, claro está, según cada autor) para que los hombres, conociendo su situación, asuman la responsabilidad de transformarla. La ilustración es por eso teoría crítica: al servicio de la práctica liberadora.

Ahora bien, este interés y esta esperanza inicial de la ilustración se enfrentan tarde o temprano con el problema del mal y del fracaso: de algún modo los hombres parecen preferir las comodidades de la ignorancia, de la propia seguridad, de los egoísmos individualistas y mezquinos, de la explotación, de la desconfianza y del sometimiento mutuo a la gran empresa emancipadora que tendrian que enfrentar. La noticia de la revolución francesa fue para Kant no sólo motivo de ilusión, sino una prueba de la esencial moralidad del ser humano. Pero sus esperanzas y también las del joven Hegel pronto se desvanecieron: la revolución terminó en la época del terror, decapitando a sus propios hijos. Napoleón, encarnación para Hegel de la Idea universal, dejo en Alemania una estela de guerras y de desorden. Probablęmente, una experiencia parecida significaron para Marx los sucesivos fracasos y derrotas del movimiento obrero, sobre todo en la Comuna de París. ${ }^{6}$

Ante el mal, el fracaso y el conflicto que por doquier parecen adueñarse de la historia universal, los filósofos ilustrados buscarán algún tipo de explicación racional: de qué sirve, dirá Kant, admirarse de la belleza y sabiduría de la creación cuando una parte de la misma -la historia universal- parece quedar fuera de los proyectos de la Providencia, sumida en el terror, la explotación y las continuas luchas de los hombres entre sí. ${ }^{7}$ Pero no hay que desesperar: así como el aparente caos del cielo estrellado sobre nuestras cabezas obedece en realidad al más perfecto orden matemático, del mismo modo será posible, piensa Kant, encontrar una logica detrás del mal y del desorden que parecen ser la única regla de la historia humana. Se trata, por así decirlo, de elaborar una "teodicea de la historia:" de mostrar que lo aparentemente cático y sin sentido tiene en realidad un orden, de mostrar que la historia es en realidad racional y que todos los males, luchas y conflictos no son un argumento contra la razón, sino una "argucia:" de la que ésta se vale para conducir al género humano hacia su liberación definitiva.

La búsqueda de una racionalidad del devenir histórico condujo a los grandes autores de la ilustración a diseñar los grandes modelos de desarrollo socioevolutivo de carácter marcadamente determinista: los grandes autores de la ilustración formulan, de uno u otro modo, una "ley" de la historia que pretende ser tan rigida y rigurosa como las leyes de las ciencias físicas. La lógica de la historia es para Kant 
un mecanismo totalmente independiente de la libertad humana. Para él, la libertad es una determinación transcendental del sujeto, que no se muestra ni se puede mostrar en el tratamiento racional y científico de la acción empírica de los hombres. La acción humana se puede explicar, mediante la aplicación de las categorías del entendimiento, como un puro mecanismo natural. ${ }^{8}$ El "progreso" y el avance en la historia son por ello independientes de la libertad trascendental del sujeto y de su cualidad moral: las simples inclinaciones naturales y egorstas de los hombres conducirán a la humanidad, a través de múltiples luchas, hacia su realización y plenitud final (la constitucion interior y exterior perfecta), porque esto es, en definitiva, lo que conviene al cálculo egoísta de los individuos. Con ello, éstos realizan sin saberlo el plan oculto de la Naturaleza.' Igualmente Hegel buscará mostrar que en el mundo histórico-político es donde plenamente se realiza su célebre aforismo que "todo lo real es racional y todo lo racional es real." Para él, la historia entera de la humanidad no es sino el desarrollo y manifestación de la Razón universal: ésta no hace más que servirse de los hombres y de su aparente sensación de libertad para realizar sus fines racionales en formas estatales cada vez más perfectas. ${ }^{10}$ También Marx, 0 al menos la lectura "oficial" de algunos de sus textos de madurez, pretendera haber dado con una "ley de la historia," tan férrea e inflexible como las leyes naturales, que parecería no dejar lugar alguno a la iniciativa de la pracis humana. ${ }^{11}$

De este modo, el mal, las constantes luchas y horrores de la historia quedan de algún modo justificados: no son obstáculo para la emancipación humana, sino más bien un medio para la misma. El conflicto es para la ilustración justamente el motor de la historia, lo que la mueve y lo que realmente la gura. Este principio tiene diversas formulaciones: en Kant, la "insociable sociabilidad" como dinamismo natural egoísta que lleva a los hombres al enfrentamiento constante con los demás; en Hegel, las guerras entre los distintos estados como dinamismo que va dando lugar a formas cada vez más avanzadas de organización polftica; en las versiones mecanicistas de ciertos manuales marxistas, la lucha de clases como principio mecénico del desarrollo y del progreso histórico. No sólo se trata en estos casos de explicaciones sobre el origen del mal y del conflicto en la historia humana, no solamente se dice con ellas que el conflicto es de hecho con frecuencia éticamente necesario e ineludible, sino que además $-\mathrm{y}$ esto es lo grave- se convierte la explotación y el sometimiento de unos hombres a otros en la dinámica misma de la historia, en principios ontologicos y racionales de la misma. Con esto no so- 
lamente se corro el peligro de legitimar a todas las victimas de la historia como "necesarias," sino que además se altera sensiblemente el proyecto inicial de la ilustración.

En primer lugar, los hombres ya no aparecen en la filosofia madura de Kant y de Hegel (y, en parte, tampoco en la de Marx) como sujetos responsables de su propia historia. En Kant era la Naturaleza humana con sus tendencias egoístas, prescindiendo de la libertad trascendental de los sujetos, el factor determinante y directivo del proceso histórico. En Hegel, la Razon absoluta como Espíritu se convierte en el mecenismo secreto y necesario de la historia universal, que ignora y se burla de la aparente libertad y responsabilidad de los individuos y de los pueblos para llevar a la historia hacia su plenitud racional. En varios textos del Marx adulto $y$ en las versiones oficiales y deterministas del marxismo ya no son las masas oprimidas quienes han de hacerse dueñas de su propia historia, como Marx pretendia en sus escritos de juventud, sino que las fuerzas productivas aparecen como un magno sujeto que, según sus leyes propias, conduce al devenir hacia su culminación en la sociedad socialista. ${ }^{12}$ En contraposición a los intereses originarios mencionados más arriba, en todas estas "versiones oficiales" o "maduras" de la ilustración, el género humano dejaria de ser propiamente el sujeto de la historia y en su lugar apareceria un macro-sujeto: la naturaleza, el Espíritu, las fuerzas productivas, etc.

En segundo lugar, si solamente hay un sujeto, no puede haber sino una sola y única historia. Toda la historia de los distintos pueblos y naciones, a pesar de su aparente diversidad e incluso de su secular aislamiento respecto a otros grupos humanos (pensemos en las culturas precolombinas), sería otra cosa que la realización y el cumplimiento de ciertas "fases" o estadios ya preestablecidos desde el principio mismo de la historia. En la naturaleza misma del hombre, en la Razón universal o en unas cuasi-eternas leyes económicas ya está desde el principio prescrito cuáles son esas fases y cuál es el orden de las mismas. La creatividad de los distintos pueblos es en este sentido irrelevante: cómodas etiquetas como "modo de producción asiático" sirven para caracterizar situaciones y culturas considerablemente diversas. En realidad todos están desde el inicio de los tiempos predeterminados a atravesar todas las etapas de una única historia. De este modo, la historicidad misma del hombre es suprimida e ignorada: en la historia no hay contingente innovación, avance y creación de nuevas posibilidades, sino que la historia es mera evolución, des-arrollo en acto de lo que, en potencia, ya está dado desde el principio mismo de la historia, ya sea en la naturaleza 
humana (Kant), en la Razón universal (Hegel), o en las leyes eternas de la materia (marxismo oficial). ${ }^{15}$ El mismo Habermas, a pesar de su crítica a la ilustración, termina aplicando a la historia los esquemas de la psicologia evolutiva de Piaget y Kohlberg," esbozando así un modelo evolutivo que prescribe universalmente una gradación de estadios de desarrollo de la racionalidad ética, que van desde las legitimaciones míticas de los así llamados pueblos "primitivos" hasta el supuesto discurso comunicativo de los avanzadísimos ciudadanos de las sociedades industrializadas (!). ${ }^{15}$

Las consecuencias políticas son obvias: la concepción ilustrada de la historia es de todo punto eurocéntrica. Tanto en Kant, Hegel como en las versiones oficiales del marxismo o en la teoría critica habermasiana, las sociedades europeas aparecen como la fase más avanzada de la historia, que está en todas ellas prácticamente a punto de llegar a la culminación final, a la realización definitiva de los anhelos de la razón. Las monarquías ilustradas en Kant, el Estado prusiano en Hegel, el socialismo "real" en los manuales stalinianos, el capitalismo tardío en Habermas, etc., son por eso también modelo absoluto de imitación prácticamente obligada para el resto del mundo. Los demás pueblos, que son vistos naturalmente como "atrasados," "subdesarrollados," etc., han de recorrer las ya prescritas etapas de la historia para llegar indefectiblemente a la situación de las naciones en la que los respectivos ilustrados viven: "Africa -decía Hegel- no ha entrado aún en la historia universal."16 Del mismo modo, Engels opina que una vez sucedida la revolución socialista en Europa y Norteamérica, "habrá un poder tan colosal y un ejemplo tal, que los parses medio civilizados vendrán a remolque. De eso se ocuparán simplemente las necesidades económicas." 17 La colonización y el imperialismo son vistos como "males necesarios e inevitables;" sus víctimas son el precio que la historia universal se cobra para realizar sus grandiosos fines racionales de civilización y progreso. ${ }^{18}$

\section{La recepción del modelo ilustrado en la teología europea}

Evidentemente, el modelo ilustrado de la historia ha encontrado importantes críticas dentro de la filosofia europea. Incluso dentro de la tradición filosófica marxista hay corrientes importantes (iy no sólo en occidente!) que no se identifican en absoluto con la concepción de la historia propia de los textos y manuales oficiales. ${ }^{19}$ Otras corrientes filosóficas de corte más académico también se han ocupado de revisar los supuestos metafísicos de este modo de concebir la historia. ${ }^{20}$ No nos vamos a ocupar aqư de esto, sino de la recepción que este modelo 
ha experimentado en la teología europea reciente, centrándonos especialmente en la obra de Rahner.

\subsection{El dilema de la teología de la historia}

Evidentemente, los esfuerzos teológicos más cercanos, espacial, temporal y sociológicamente a los grandes pensadores ilustrados, resienten la huella del gran intento moderno de pensar la historia según el modelo moderno (y burgués) de racionalidad. La teología repiensa sus temas tradicionales de un modo acorde a esta visión del devenir histórico. Jesús, por ejemplo, aparece retratado como un maestro y campén moral, portador de los valores de racionalidad, libertad y progreso típicos de la ilustración. ${ }^{21}$ Aunque pronto se comienzan a ver los límites de este modo de pensar, no resulta fácil librarse de sus consecuencias si se aceptan sus presupuestos. El enfrentamiento teológico con la concepción ilustrada de la historia se encuentra, por así decirlo, ante un dilema.

Por una parte, si se quiere de algún modo asegurar la libertad humana en el encuentro con Dios y, con ello, la posibilidad de pensar de algún modo la salvación, es claro que la historia real y empírica, tal como la concibe la ilustración, no parece el lugar más adecuado para situar la salvación. En el pensamiento de Kant, por ejemplo, resulta claro que la actividad concreta del hombre ha de concebirse según las mismas categorías que los fenomenos del mundo físico. Y allf, claro está, no hay ningún lugar para la libre acción de Dios y del hombre. La libertad, la moralidad y, por tanto, también el tema de Dios son situados fuera del plano espacio-temporal, en el nivel de la subjetividad transcendental.

Este esquema, asumido teológicamente, significa lo siguiente: la salvación y el encuentro con Dios no se realizan en el ámbito de la historia empírica de la humanidad, sino en un plano puramente transcendental: "la historia de la salvación neotestamentaria -afirma Cullmann - se distingue radicalmente de toda otra historia," y consiste en la selección de determinados hechos que Dios escoge y ordena a su modo, y que para el creyente resultan solamente accesibles en la fe. De este modo, la historia profana y la historia de la salvación aparecen como dos procesos paralelos e independientes entre sf: la salvación no concieme a la historia "mundana" y los acontecimientos histórico-salvíficos que en esta aparecen (Jesús, por ejemplo) no tienen especial relevancia dentro de la misma, sino que constituyen una unidad de significado más bien arbitraria que contradice a la — supuesta - "ley de continuidad de la historia." ${ }^{22}$ 
Por otra parte, parece todavia más grave querer evitar tan marcado dualismo: la única alternativa posible dentro de esta concepción de la historia pareciera ser la identificación de la historia de la salvación con el progreso de la hiotoria universal. No es necesario, claro está, llegar al extremo de Hegel, quien convierte la historia en una verdadera teogonía del Espiritu absoluto, y por tanto en verdadero y único "juicio final" (Weltgericht), con lo que las victimas del "progreso" quedan también condenadas difinitivamente ante tan alto tribunal. Desde otras categorias teológicas es también posible identificar la historia de la salvación con la historia universal de manera tal que las naciones, las culturas o las religiones más "avanzadas" y "desarrolladas" serian de algún modo las que mejor habrian realizado o expresado temáticamente el proyecto salvifico de Dios.

Para Pannenberg, por ejemplo, no hay más que una historia, la historia profana que es a la vez la historia de la salvación. Qué sea la salvación es algo que se ha de entender primariamente desde la siempre parcial felicidad terrena de los individuos y de los grupos sociales. Dios es el Señor de la historia; el hombre no es por tanto propiamente el sujeto de la misma, sino su tema. La tematización de la salvación del hombre en la historia tiene lugar a través de la experiencia religiosa. Sobre el mayor o menor valor de esa tematizeción no decide una autoridad infalible, sino la razón humana, la cual compara criticamente las distintas religiones para concluir que la judeo-cristiana es la que mejor ha tematizido la revelación de Dios y, con ello, la salvación del hombre, justo por concebirlas históricamente. ${ }^{23}$ El peligro que de ahr se deriva es la minusvaloración del significado salvífico de la $\mathrm{cruz}^{24}$ y la identificación de la historia de la salvación con la historia de la revelación, y en definitiva con una determinada tradición religioso-cultural, que resulta ser la de occidente. Que Dios se pueda revelar preferentemente en los "Cristos azotados de las Indias," como decía Las Casas, ${ }^{25}$ y no en el cristianismo de sus azotadores, no es tan fácil de explicar desde esta teología

\subsection{El punto de partida de $K$. Rahner}

La reflexión teológica de $K$. Rahner sobre la historia presenta, a mi modo de ver, algunos elementos que la capacitan para un enfrentamiento más crítico con la perspectiva ilustrada. ${ }^{26}$ Dos rasgos fundamentales de su pensamiento son de importancia para el tema que nos ocupa: por una parte, Rahner se distancia de las aporías a las que había conducido la reflexión tradicional sobre el tema de la 
relación entre naturaleza y gracia (cfr. NG, 339), introduciendo su conocido concepto del "existencial sobrenatural:" en el fondo se afirma que la realidad humana tal como la conocemos hoy está ya constituida por la gracia y que, por tanto, la "naturaleza" de la teología escolástica no ha de ser considerada como un concepto-residual, un Restbegriff (NG, 340). De este modo, se abre la puerta a consideraciones menos metafísicas: (en el pero de los sentidos) y més historicas de la salvación: el concepto opuesto a "gracia" no es necesariamente la naturaleza, sino el pecado en todos sus aspectos. ${ }^{27}$

Por otra parte, Rahner intenta superar el concepto kantiano de libertad, recibido en su caso de la tradición neo-escolástica, con una reflexión de acentos más existenciales: el hombre es para él una unidad indisoluble de concreción corpórea (lo que Rahner denomina "lo categorial") y apertura a la transcendencia (cfr. GG., 35-53). Por eso mismo no se puede reducir la libertad a un dato empírico concreto, pero tampoco se la puede separar, como pretendía Kant, de la realidad espacio-temporal e historica del hombre (cfr. GG, 47). La libertad no es, como pretendía la ilustración, un siempre-poderdecidir-de-nuevo, sino más bien la capacidad de realizarse definitoria y definitivamente ante los demás y ante Dios (cfr. GG, 102). Tampoco es una propiedad "que habite tras la temporalidad física, biológica o histórica del hombre, sino que se realiza (...) justamente a través de esa temporalidad" (GG, 101). La libertad es más bien "el carácter definitivo del hombre ante Dios en la historia" (PH, 12ss).

\subsection{Historia de la salvación e historia profana}

Todo esto tiene, claro está, consecuencias inmediatas para su teologia de la historia. Por una parte, la libertad humana, a pesar de todos sus condicionamientos psicológicos, sociales o políticos, no es algo extranio a la historia, sino que es un elemento integrante de la misma. El hombre permanece libre y por tanto responsable: es imposible entregar la responsabilidad por la historia y sus victimas a los ciegos mecanismos, a la naturaleza o a la Razón absoluta. El género humano, con su siempre limitada libertad, es inevitablemente el verdadero sujeto de la historia, y ningún macro-sujeto metafísico le puede arrancar esta pesada carga. Por esto mismo, por mucho que la historiograffa necesite esquemas metodológicos (como el de "modo de producción asiático"), estos esquemas no pueden ya concebirse como fases necesarias del desarrollo histórico, todo pueblo ha de atravesar indefectiblemente en virtud de un imperativo de corte cuasimetafísico. El devenir histórico no posee una unidad y unas pautas universales de desarrollo que le hayan sido dadas de antemano. 
Cuando Rahner insiste en la unidad, ésta no es concebida más que como un hecho al que la historia se estaba aproximando en el momento de la encarnación, no en virtud de una necesidad metafísica a priori, sino como resultado de la praxis humana misma (cfr. GG, 146 ; 165ss).

Por otra parte, dada la unidad del ser humano y de su libertad, el encuentro libre del hombre con Dios esté siempre categorial e históricamente mediado. La histórica salvación del hombre no ha de acontecer en un ámbito distinto del de la historia (Kant, Cullmann), sino a lo largo de la historia mundana misma, estrechamente unida a ella. Si a esto se le añade la doctrina rahneriana del existencial sobrenatural, hay que afirmar que la realidad humana está "elevada" (cfr. GG, 132ss), y que la salvación es una realidad ya presente en todos los hombres (cfr. NCR, 343). Por estar la transcendentalidad del hombre siempre categorial e históricamente mediada, hay que afirmar que "el mismo existencial sobrenatural tiene una historia" individual y colectiva (cfr. GG, 146 y PH, 21-22). "Hay ciertamente," dice Rahner, "una historia de las luchas de clase; pero en el interior, en el fondo y por encima de estas luchas sociopolíticas tiene lugar una historia de la libertad, de la fe, de la esperanza y del amor ante Dios y en dirección hacia su vida eterna" (PH, 11). La salvación no es por todo ello algo que afecte sólo a una determinada región del mundo o de la historia (lo "religioso," lo "santo," etc.), sino que la historia de la salvación es coextensiva con la historia entera de la humanidad (cfr. GG, 149; WH, 116-117): "no hay ninguna acción salvadora del hombre que no sea al mismo tiempo hacer salvífico de Dios" (GG, 147).

Sin embargo, el que sea coextensiva no significa para Rahner que sea idéntica (cfr. WH, 119ss). Y esto, por dos razones. Por un lado, la libertad de Dios en su entrega a los hombres: la salvación, es en definitiva, Dios mismo y por más que ya se le pueda descubrir mediatamente en la historia, el encuentro definitivo con él no se deja someter a los condicionamientos históricos, sino que es la superación misma de la historia en la visión beatífica (cfr. WH, 120). Por otra parte, la libertad del hombre: la última cualidad de la libertad humana permanece siempre oculta a la historia universal: si en una determinada decisión el hombre acepta definitivamente a Dios o se cierra a él es algo que no se puede decidir definitivamente en vistas a los datos objetivos y empíricos que hay en la historia. En virtud de criterios éticos podemos suponer, esperar o temer, pero no podemos juzgar (cfr. WH, 119-120). La historia universal no es la palabra final sobre sí misma, como pretendía Hegel. El último sentido de la historia como salvación universal permanece por tanto oculto en Dios 


\section{(cfr. PH, 16).}

Esta afirmación es enormemente importante, pero insuficiente. Es importente porque la no-identidad entre historia de la salvacion e historia universal le salva a Rahner del peligro que vimos a referimos a Pannenberg: la legitimación de los "triunfadores" de la historia, identificando sus éxitos y progresos con la salvación misma, lo cual mucho tiene que ver con Hegel y poco con las afirmaciones del sermón de la montaria o de Mateo 25, 31-46. El problema consiate en que Rahner ha tenido que pagar un precio muy alto para evitar tal identificación. Si la última cualidad de la liberted humana permanece oculta, se podria pensar entonces que cualquier acontecimiento histórico puede ser una mediación de la salvación. Rahner mismo admite que hechos aparentemente inmorales y depravados pueden realizar esa mediación (cfr. NCR, 348). Pero entonces, len virtud de qué criterios decimos que el amor y no el odio, que la liberación y no el genocidio conciemen directamente a la salvación cristiana?

Rahner evita el peligro de la arbitrariedad recurriendo a los "signos" de la salvación que en la historia universal se hacen presentes. En virtud del "existencial sobrenatural" se puede afirmar que la salvación es ya una realidad operante, aunque en distinta medida, en todos los hombres, sean o no creyentes (cfr. NCR, 347; GG, 176). El cristiano, claro está, interpreta todo suceso histórico desde la "revelación especial" acaecida en Jesucristo (cfr. GG, 161ss, 177; WH, 129; NR, 348; PH, 18). Desde esta perspectiva, toda la historia tiene para el cristiano un sentido: la aceptacion incondicional de Dios por todos los hombres que ha de culminar en la visio beatifica. Este "sentido" es, según Rahner, la verdadera "Entelequia" del devenir historico (cfr. GG, 123-124; NR, 345). Si bien la realización concreta de este último sentido es más bien un misterio que solo se puede esperar, lo cierto es que, desde ese punto de vista, determinadas coyunturas históricas en las que se hace presente el amor a la liberación pueden ser interpretadas por los cristianos como verdaderos "signos de la salvación."

Rahner comprende estos signos bajo el denominador común de "amor al prójimo," no sólo en un sentido individual, sino también social e histórico: amor a la clase oprimida o a los pueblos del llamado tercer mundo (cfr. PH, 21). La razón de concebir así estos signos es una vez más la estructura transcendental del ser humano, tal como Rahner la ha definido. La transcendentalidad humana, en cuanto posibilidad de una experiencia se da solamente en el encuentro con un determinado objeto real, y está siempre medida por el recono- 
cimiento de un Tú personal (crf. NL, 284). La apertura a un Tú es un momento esencial y constitutivo de la subjetividad humana, de tal modo que el hombre solo puede ser verdaderamente libre mediante el encuentro concreto y real con otros hombres (cfr. NL, 287-288). Solamente quien está ya a priori referido a un Tú y quien en prioridad lógica ya tiene la experiencia de un Tú humano puede realizar la experiencia transcendental de su referencia al misterio absoluto que llamamos Dios (cfr. NL, 293). El amor a Dios es posible por ello en la apertura confiada que tiene lugar en el amor al projimo. $\mathrm{Y}$ el amor al prójimo, también en sus dimensiones colectivas, es entonces el acto primero del amor a Dios (cfr. NL, 295). De este modo es posible afirmar que allí donde se realiza individual, social o políticamente este amor, hay un signo de la presencia real de la salvación.

\subsection{Pervivencia de los presupuestos ilustrados}

Como veremos, hay en esta reflexión de Rahner sobre la historia importantes puntos de contacto con la perspectiva de Gutierrez. No obstante, hemos de considerar aquí también algunos de sus límites. En primer lugar, Rahner afirma la necesidad de no identificar la historia de la salvación con la historia profana para salvaguardar la libertad de Dios. Ahora bien, hay que preguntarse si realmente la libertad de Dios queda rebajada si afirmamos que Dios mismo ha querido libremente hacer de esta nuestra historia profana una historia de la salvación, y que eso es lo que nos ha manifestado justamente en su revelación. Dios puede perfectamente haber dispuesto que la partida de la salvación definitiva del hombre, de su libre aceptación o rechazo de Dios, se juegue precisamente en esta historia. Pues, ¿dónde se habría de jugar si no? ¿No es eso justamente lo que pone de manifiesto la encarnación del Hijo? A mi modo de ver, en el fondo de este recelo de Rahner se esconde un presupuesto típico de la concepción ilustrada de la historia profana: se piensa que el devenir histórico de algún modo esté sometido a leyes férreas que poco espacio dejan a la libertad del hombre y de Dios. Y por ello se sitúa (pensemos en Kant) el encuentro definitivo con Dios en un plano distinto, transcendental. Rahner ha insistido en que esa transcendentalidad está siempre categorialmente mediada. Lo que habrá que ver es si esa solución es suficiente o no.

Consideremos entonces, en segundo lugar, la otra razón aducida por Rahner: la última cualidad de la libertad humana no nos es accesible y por ello no podemos juzgar. A mi modo de ver, Rahner ha confundido aquí el plano epistemologico con el ontológico: una cosa es 
que nunca podamos saber con certeza definitiva si una determinada acción, sean cuales sean sus apariencias, es o no una definitiva aceptación libre de Dios, y que por eso no podamos juzgar (nuestra limitación epistemológica; sólo Dios conoce lo profundo de los corazones). Y otra cosa muy distinta es que eso que Rahner llama "la cualidad última de la libertad" no pertenezca a nuestra historia, sea un tipo de realidad distinta, ajena al devenir histórico. $Y$ aquí es donde se descubre en Rahner la pervivencia del esquema kantiano: cuando Rahner da una definición de lo que él entiende por historia (cfr. WH, 123-124), pues la salvación no concierne a lo empírico y categorial, sino a la subjetividad transcendental del hombre.

Rahner trata, claro estí, de sortear el dualismo kantiano, pero moviéndose en definitiva en sus mismas categorías. Por eso, por mucho que insista en que lo transcendental está siempre categoricalmente mediado, se trata inevitablemente de una mediacion entre dos realidades ajenas entre sí La salvación no concierne a la realidad fenoménica de la historia, sino a la subjetividad transcendental. Ella es para Rahner el auténtico objeto de la acción salvadora de Dios, y no la historia mundena, que pertenece a un plano meramente empírico. Esto se ve claramente en su concepción del amor al projimo como lugar preferencial de la mediación entre salvación e historia profana: a pesar de todos los intentos de Rahner, éste no puede evitar el instrumentalismo: el projimo es la ocasión de que mi subjetividad transcendental se abra al misterio absoluto de Dios. Pero lo que está propiamente en juego es $m i$ subjetividad transcendental y no el projimo como tal. El projimo, en esta perspectiva, no deja de oer una pura mediación categorial de mi apertura transcendental a Dios. EI evangelio de Lucas, en cambio, altera radicalmente el contro de la cuestión: no se trata de saber quién es mi projimo, sino de decir quién fue próximo al necesitado (Lc 10, 30-37).

Desde un punto de vista filosofico, hay que preguntarse si, en definitiva, la idea de transcendentalidad que maneja Rahner ha superado los presupuestos filosóficos de la ilustración. ¿Es la apertura transcendental una propiedad del sujeto o es más bien primariamente un carácter de la realidad misma? No ciertamente en el sentido de los transcendentales clásicos de la escoléstica, inseparables de una metafísica conceptivista del ser hoy poco defendible. Pero sí como un carácter de la realidad presente en la actividad sentiente del hombre. ${ }^{23}$ Si así se concibiera la transcendentalidad, sería más fácilmente pensable la ubicación del "lugar" (teologal) de la transcendencia no en el viejo sujeto kantiano y en sus preocupaciones morales o existenciales, sino justamente en el necesitado. 
Hemos reconocido ciertamente un valor critico en la distincion rahneriana entre historia de la salvación e historia profana al impedir la identificación ideológica del progreso de la cultura occidental con el plan de ealvación, como algunos teologos europeos podrfan pensar. Como Rahner bien dice, la cruz permanece alzada sobre la historia. Pero para mantener esta distancia crítica no es necesaria la dualidad ontologica de dos historias, sino más bien pensar la historia con categorlas distintas de las ilustradas: si la historia es puro desarrollo de potencialidades ya dadas desde un principio, es obvio que la salvación, de suceder en esta historia, se identificaría con el desenvolvimiento progresivo de esas potencias. En cambio, si el devenir hist6rico consiste en entrega contingente de posibilidades, es perfectamente pensable que el fracaso y la misma muerte puedan resultar salvificamente decisivas, en cuanto apertura de nuevas posibilidades que poco tienen que ver con el progreso en el poder cientifico-técnico. La cruz, si, permanece alzada sobre la historia, pero sobre esta única historia que es también historia de salvación. Esto es lo que hemos de ver en Gutiérrez.

\section{La concepción de la historia en la teología de Gutiérrez}

\subsection{Punto de partida: opción por los pobres}

Para comprender adecuadamente el enfoque del problema de la historia en la teología de Gutiérrez es menester comenzar por referirse al punto de partida mismo de esta teologia, que constituiría precisamente la diferencia decisiva con la tradición teologica europea (cfr. FH, 215-290). El interlocutor y el destinatario de la teologia latinoamericana no es la nueva civilización burguesa y secular surgida en Europa a partir de la ilustración, sino el mundo pobre: no se trata por eso de recuperar teologicamente los impulsos críticos y emancipadores de la ilustración, al estilo de la teología política, sino de hablar de Dios desde las víctimas de la historia, que no dejan de ser en buena medida también las victimas de la mentada civilización. La opción por los pobres de la Iglesia latinoamericana es el "hecho mayor" a partir del cual surge la teología como "acto segundo;" es decir, como reflexión crítica sobre la praxis liberadora a la luz de la palabra de Dios (cfr. TL, 21-41).

Este punto de arranque de la teologia latinoamericana está sostenido por una experiencia espiritual fundamental: el descubrimiento del rostro de Jesucristo en las mayorías pobres y oprimidas del continente (cfr. TL, 250-255; FH, 69-72, passim). Los pobres en quienes se hace presente Jesucristo, y no los problemas existenciales 
del sujeto, por importantes que éstos sean, constituyen el centro de la espiritualidad de la liberación (cfr. BPP). El "lugar teológico" fundamental no es la conciencia del hombre moderno, sino el "otro" de la historia (FH, 52, 54), el "pueblo profundo" de América Latina. En esta experiencia, el projimo no es sin més cualquier "Tí personal," sino preferentemente el pobre, el necesitado y oprimido (cfr. Mt 25, 31-46). La revelación del amor libre y gratuito de Dios, no en los "sabios e inteligentes," sino en "el pueblo sencillo" (Mt 11, 25-25) determina un nuevo modo de hacer teologia, un nuevo método teológico (cfr. HD, 1418). Pues solo desde la aprehensión primordial que se da en la mística y en la préctica es posible un logos "auténtico y respetuoso" sobre Dios (cfr. HD, 17; véase también TL, 387s).

Este método teológico está sin duda cargado de consecuencias para los contenidos mismos de la teología. Así, por ejemplo, los "signos" de la salvación cobran un significado radicalmente nuevo: éstos no consisten en la mediación de la apertura de mi subjetividad hacia Dios, sino más bien la "salud" del pobre (pensemos por ejemplo en los milagros del Nuevo Testamento como signos del reino). Ciertamente, la salvación concreta y real del pobre no agota todo el contenido de la salvación cristiana, pero la "significa" real e históricamente. De este modo, no cualquier hecho histórico es igualmente susceptible de mediar la salvación: la perspectiva del pobre (iy no el "progreso" de la civilización!) es el criterio fundamental para detectar qué hay de salvación y qué hay de perdición en la historia. ${ }^{29}$

\subsection{Mas allí del dilema de la teología clásica}

Todo esto, claro está, tiene muchas más consecuencias importantes para nuestro tema. Para la teología de la liberación el problema no consiste primariamente en conciliar el progreso $0, y$ el avance histórico con el plan de salvación, ya sea mostrando la independencia de los dos planos (Kant, Cullmann, en parte Rahner), ya sea subrayando la coincidencia del desartollo cultural y tecnológico con los designios divinos (Hegel, en parte Pannenberg), sino en "releer la historia" desde los "vencidos" de la misma (cfr. FH, 259s). Y, para hacer esto, la teología de la liberación parte de la conciencia actual de la insuficiencia de las soluciones clásicas.

Por una parte, la crisis del esquema de la distinción de planos: la teología de la liberación hereda de la teología contemporánea la conciencia clara de la insuficiencia de las distinciones tradicionales entre lo sagrado y lo profano, entre lo mundano y lo transcendental (cfr. TL, 98-102), entre naturaleza y sobrenaturaleza. En este punto, 
Gutiérrez nombra expresamente la contribución de Rahner: habiendo convertido la "naturaleza pura" de la escolástica en un Restbegriff, se abre la puerta a una concepción más existencial e histórica de la salvación. El único hombre que históricamente conocemos es el efectivamente llamado al encuentro con Dios. Esto conlleva la recuperación de la conciencia de la unidad de la vocación divina: todos los hombres están llamados a la salvación y en ellos actúa ya la gracia. En este sentido hay que afirmar al menos, como Rahner, la coextensión de la historia de la salvación con la historia universal (cfr. TL, 102-190). Queda en pie, sin embargo, la cuestión de si es verdaderamente necesario seguir hablando de dos historias.

Por otra parte, las esperanzas puestas inicialmente por algunos téricos sociales y también por algunos sectores de la Iglesia en un rápido desarrollo de América Latina como prolongación del desarrollo de los grandes centros capitalistas se vieron pronto defraudadas. Al optimismo histórico del "desarrollismo" (que no deja de ser una continuación del optimismo ilustrado) pronto se affadió la conciencia de una profunda dependencia que impide estructuralmente cualquier mejora social y económica dentro de los cauces previstos, tendiendo más bien a ahondar las diferencias (cfr. TL, 113-134), como el problema actual de la deuda externa no deja dolorosamente de recordar. Para la teologia, esto significa el imperativo de no identificar precipitadamente cualquier desarrollo histórico con el avance mismo de la salvación, sino más bien de distinguir cuidadosamente entre las distintas dimensiones del progreso, pues el avance científico-técnico puede ir unido a cotas enormes de opresión socio-política: tanto nacional como internacionalmente (cfr. $\mathrm{TL}, 232$, 277).

He aqui el grave problema: por una parte se quiere pensar la salvación en la historia real de los hombres, y no fuera de la misma. Pero, por otra parte, la teología latinoamericana arranca de la clara conciencia de lo peligroso que es identificar sin más cualquier desarrollo histórico con la salvación. Ninguno de los dos términos en los que se planteaba el dilema a la teología europea (o dos historias o la pura identificación) es ya aceptable.

Pero la pregunta es más bien si ese dilema está correctamente planteado, pues éste es en el fondo la consecuencia de una teodicea de la Providencia, de la Naturaleza o de la Razón que convertía el mal y sus victimas en la historia en el precio "necesario" para el triunfo definitivo del bien y del progreso. La legitimación de tales víctimas es, sin embargo, algo muy difícil de presuponer cuando se quiere hacer teología desde el contacto, la amistad y la solidaridad real con 
los oprimidos. 30 Desde ahi, el problema no consiste primariamente en mostrar la racionalidad de la historia; no se trata tampoco de "justificar" la existencia de Dios y su relevancia para la historia frente a una concepción secular, "cientifica" y mecánica de la misma, oino más bien de "justificar" al pobre en sus luchas, en su resistencia y en eu esperanza. $O$, en términos de Gutiérrez, de "hablar de Dios desde el sufrimiento del inocente," desde la experiencia de Job (cfr. HD): allí no es posible banalizar el problema del mal, sino hay que enfrentarlo en toda su radical crudeza. Si se quiere hablar de un "sentido de la historia" (TL, 265, 272, 387), éste hay que buscarlo en los pobres, que son el cuerpo de Cristo en la misma; en su pasión y resurrección, y no en una conciliación metafisica de desarrollo histórico y salvación. Pero para hacer esto es menester situarse más allá de muchos presupuestos filosóficos y teológicos de la ilustración. Ea lo que hemos de ver en el siguiente apartado.

\subsection{La oubversión de la historia}

Partir de la perspectiva del pobre significa constatar la progresiva percepción, por parte de las mayorfas oprimidas, de lo inaceptable de su situación (cfr. $T L, 44$ ), contribuyendo al mismo tiempo a iluminar esta toma de conciencia desde la palabra de Dios. El fin al que apunta esta concientización no es otro que el que los pobres mismos pasen a ser los sujetos de su propia historia, ${ }^{32}$ y no sólo sus víctimas (cfr. TL, 132s, 148, 153, 160s). Sujetos tambiên de la evangelización, y no sus simples destinatarios; sujetos de la teología, y no meramente el "tema" de la misma (cfr. TL, 387; FH, 87, 268s). Que los pobres pasen a ser sujetos de la historia significa no solamente releerla, sino rehacerla desde abajo: "será, por tanto, una historia subversiva. Hay que convertir la historia no desde arriba, sino desde abajo" (FH, 32).

Ciertamente, la teología de la liberación es consciente de las dificultades a las que se enfrenta semejante tarea (cfr. FH, 96-98; HD, passim), pero la fidelidad al rostro de Cristo que se manifiesta en los oprimidos es un continuo acicate que impide la entrega del proyecto histórico en manos de algín "macro-sujeto" que, en virtud de algún tipo de ciega necesidad, lleve la historia a un buen fin. Se puede decir que la esperanza contra toda esperanza en el "Dios de los pobres" es justamente lo que evita que la teología de la liberación renuncie a su fidelidad a las víctimas de la historia para confiar, como hizo la ilustración, en que la historia, en virtud de algún tipo de determinación metafísica, se libere a sí misma. Dios no es para la teología de la liberación el sabio ordenador del cosmos y de la historia, como lo ha sido frecuentemente para la filosofía y para la 
teología europeas, sino el Go'el, el Dios liberador que toma partido por los oprimidos (cfr. HD, 123-124).

Esta confienza fundamental en Dios y en los pobres exige un nuevo tipo de conceptuación de la historia, en la cual los hombres reales de carne y hueso aparecen como sujetos de la misma (cfr. TL, 52-62). Lo cual no significa, claro está, pasar por alto los múltiples condicionamientos reales a los que la praxis histórica está sometida, sino más bien subrayar que, con todo, es la humanidad real, y no la Naturaleza o la Razón quien hace la historia. Justamente por eso es que se puede esperar, en primer lugar, que los pobres puedan llegar a ser algún día sujetos de su propia historia. Y por eso mismo es posible también, en segundo lugar, exigir responsabilidades a los actuales "señores de la historia," pues sus víctimas no son meros productos de la necesidad, sino consecuencias de un pecado socialmente estructurado. Cuando la teologia de la liberación habla de "pecado estructural," no lo hace como algunos ingenuos $\longrightarrow$ mal intencionadosapresuradamente entienden, para ocultar las responsabilidades personales en el mismo, sino justamente, por el contrario, para indicar que las estructuras socio-económicas no se pueden entregar sin más a sus "férreas leyes" (argumento típicamente conservador), pues tras ellas siempre hay una responsabilidad ante Dios y ante los demás hombres por parte de sus beneficiarios y defensores (cfr. TL, 67).

Filosóficamente, todo esto implica reconocer el valor central de la actividad humana y la "ruptura epistemológica" fundamental que la "filosofia de la praxis" representa respecto a toda la tradición filosofica precedente (cfr. TL, 57). ${ }^{\text {ss }}$ En esta perspectiva, los hombres aparecen como los sujetos transformadores tanto de la naturaleza externa mediante el progreso científico técnico, como de su propia realidad espiritual, social y política (cfr. TL, 209, 232ss, 277, 374; FH, 64-68, 218ss). Si los hombres son y permanecen sujetos de la historia, ésta no puede consistir en el desenvolvimiento en acto de unas supuestas potencialidades ya prescritas desde el comienzo de la historia. A diferencia de la tradición filosofica en la que se mueve la ilustración, hay que afirmar que "la historia, contra toda perspectiva esencialista y fijista, no es el desarrollo de virtualidades preexistentes en el hombre, sino la conquista de nuevas formas (...) de ser hombre" (TL, 62). Evidentemente que en la historia hay avances y mejoras cualitativas, pero éstas no se entienden como desarrollo de la racionalidad o de la libertad, tal como pretendía la ilustración, sino como acumulacion - siempre contingente- de experiencias y logros pasados de la humanidad en cuanto fuente de nuevas posibilidades 
(cfr. TL, 43). El evangelio no viene a confirmar el proceso evolutivo, como pretenderia cierta teología liberal, sino justamente a anunciar la gran posibilidad de la fraternidad humana en la historia (cfr. TL, 352).

Desde este punto de vista resulta entonces claro que el "progreso" no es un proceso mecánico y necesario, sino una tarea abierta. También es por ello evidente que la historia no pueda comprenderse como una unidad de desarrollo ya prescrita, en la que solamente habría un camino que todos los pueblos habrian de recorrer, atravesando una serie ya determinada de fases, segín las cuales sería posible ordenar gradualmente a las distintas culturas y naciones, atendiendo a su mayor o menor cercania al supuesto fin de la historia, el cual estaria a punto de ser alcanzado por occidente, modelo para el resto del mundo: "Los parses subdesarrollados aparecen así como países atrasados, situados en etapas anteriores a la de los pueblos desarrollados, obligados, por consiguiente, a repetir, más o menos, la experiencia de éstos últimos en su marcha hacia la sociedad moderna. Sociedad caracterizada, para quienes se sitúan en el corazón del imperio, por un alto consumo en masa" (TL, 115). Pero "a los países pobres no les interesa repetir el modelo de los países ricos, entre otras cosas porque están cada vez más convencidos de que la situación de aquéllos es el fruto de la injusticia, de la coerción. Para ellos se trata de superar, es cierto, las limitaciones materiales, la miseria, pero para llegar a un tipo de sociedad que sea más humana" (TL, 44). Nada más lejano al esquema evolutivo de la ilustración.

La unidad del devenir histórico no consiste, por tanto, en la unidad de un proceso mecánica y metafísicamente predeterminado, sino en un simple hecho, por lo demás contemporáneo: es una unidad creada historica y contingentemente por la praxis humana (cfr. TL, $101,210,360$ ), tanto en un sentido negativo (la interdependencia actual de la humanidad entera es en buena medida fruto del imperialismo y del colonialismo), como en un sentido positivo (unidad como proyecto de superación histórica de todo lo que divide y separa a los hombres). Esta afirmación nos distancia tanto del concepto de progreso de la ilustración como de las veleidades "postmodernas" de algunos filossofos y té́logos que, pasando por alto la real interdependencia del mundo actual, se refugian románticamente en la diversidad de sentidos, de culturas, de tradiciones (restos de una real independencia en el pasado), como si esta pluralidad determinara sin más la existencia actual de diferentes líneas históricas. La historia no consiste ni primaria ni únicamente en "sentido," sino en praxis real, y 
por eso la diversidad cultural, que es algo enormemente valioso, no puede servir para ocultar el hecho de la unidad económica y política de la humanidad actual, construida a sengre y fuego por los colonizadores europeos y mentenida en las actuales estructuras de opresión y de dependencia. Esto es lo que la teologia de la liberación quiere subrayar cuando habla de la unidad actual de la historia (cfr. $T L, 121$ ), y desde esta unidad es desde dónde hay que entender la denuncia del profundo abismo entre ricos y pobres que, en virtud de los dinamismos del orden economico internacional, amenaza con una profunda division de la humanidad (cfr, TL, 123), tal como subraya por cierto una reciente enciclica. ${ }^{\text {sh }}$

Desde esta superación de muchos prejuicios ilustrados se entiende que la opción preferencial por los pobres no se base en que éstos, en virtud de un mesianismo inserto en la dialéctica de la historia, vayan a ser los seffores del mañana;; ni tampoco en sus supuestas disposiciones morales o espirituales, vino solamente en el amor gratuito de Dios (cfr. FH, 118; HD, 15-16). Del mismo modo, las luchas y conflictos sociales no son integrados en una teodicea de la historia, convirtiéndolas en un motor metafísico de la misma, como sucedía en el pensamiento de la ilustración. El motor de la historia es para Gutiérrez otro, como veremos. El conflicto no es una teorfa o un programa, como con frecuencia se piensa en algunos ambiente eclesiásticos, sino un hecho (cfr. TL, 352-356, 44) que consiste primariamente en la explotación de unos hombres por otros (cfr. TL, 78ss). Como hecho, y no como doctrina, es experimentado cotidianamente por millones de hombres y mujeres en el tercer mundo. El primer imperativo del té́logo es reconocer este dato y no refugiarse en vaguedades aparentemente conciliatorias que no sirven más que para legitimar la pervivencia de esa explotación (cfr. TL, 178sa). La superación del conflicto no sucederá en virtud de una secreta razón dialéctica de la historia, como pretendería Hegel, sino que constituye una tarea abjerta, la cual es siempre de algún modo conflictiva, no por gusto de los oprimidos, sino justamente en virtud de la resistencia de los opresores (cfr. TL, 356ss)

\subsection{Salvación en la historia}

Hemos visto más arriba cómo Gutiérrez hereda de la teologia europea contemporánea la crisis del esquema de la distinción de planos. Sin embargo, esa teologia, presa todavia de los presupuestos filosóficos de la ilustración, no lograba dejar de hablar de dos historias, por más que éstas fueran consideradas como coextensivas. Ahora bien, una vez superados esos presupuestos, es posible pensar 
de un modo nuevo las relaciones entre salvación e historia sin caer por ello en la mera identidad. Para esto Gutiérrez apelará a varios motivos bíblicos y teológicos.

En primer lugar, conviene recordar que el pecado, siendo ciertamente una ruptura del hombre con Dios, "es también una realidad histórica, es quiebra de la comunión de los hombres entre ellos, es repliegue del hombre sobre sí mismo" (TL, 198, cfr. 224). No se trata simplemente de que primero se dé el pecado en la esfera individual, privada, al margen de la historia y que después este pecado se encarne en estructuras históricas. Más radicalmente hay que decir que todo pecado, incluso cuando éste no se cristalice inmediatamente en estructuras injustas, es algo que sucede en la historia y no fuera de ella (cfr. TL, 236-239). Es un prejuicio de estirpe ilustrada pensar que solamente el "espíritu objetivo" (estructuras, instituciones) pertenece a la historia, y no lo privado y subjetivo. Ciertamente hay una diferencia en el sentido de que las posibilidades de "juzgar" plano epistemológico) son muy distintas en uno y otro caso. Ahora bien, si el pecado es una realidad histórica, también la salvación cristiana como liberación del pecado en todos sus aspectos -personales y estructurales - concierne directamente a la historia profana y no a una metahistoria (plano ontológico).

En segundo lugar, todo esto se entiende mejor si recordamos que el hombre aparece en la Biblia, a diferencia de la tradición filosófica occidental, como una unidad indivisible (cfr. TL, 223), y el llamado a la salvación concierne por tanto a la realidad humana entera, también al cuerpo. Y esto, no en un sentido individualista, como ha tendido a interpretarlo la teología europea, pues no se trata tanto de $m i$ cuerpo, sino del "cuerpo débil y desfalleciente del pobre" (cfr. BPP, 133-137). El dualismo antropológico era en la filosofia y teologia tradicionales justamente el fundamento de la distinción entre el mundo de la historia empirica, fenoménica, categorial, y el ámbito de la subjetividad transcendental, donde realmente acaecería la salvación. Pero si el hombre es una unidad hay que extraer entonces dos consecuencias. Por una parte, todo su ser está atravesado de historicidad, y no solamente una parte del mismo. Por otra parte, el llamado a la salvación concierne entonces a toda la realidad humana y a toda su historia. El reduccionismo no consiste en decir que Dios quiere salvar la historia entera en todos sus aspectos sino, por el contrario, en decir que sólo una parte de la misma (lo "espiritual") es afectada por la redención (cfr. TL, 240). Si Cristo es el Señor de la historia, no se puede dejar fuera de su obra redentora ninguna parte de la misma (cfr. FH, 272). El llamado de Dios a la salvación acontece 
históricamente en la historia real de la humanidad y la incluye (cfr. TL, 102-109).

En tercer lugar, todo esto se puede comprender desde la continuidad, en sentido brblico, entre creacion y salvacion. Israel no parte de la creación para después pensar la salvación, como sería propio de la mentalidad cosmológica y naturalista de los griegos, sino que, por el contrario, piensa la creación desde la historia. "La creación es presentada en la Biblia no como una etapa previa a la salvación, sino como el primer acto salvífico" (TL, 201). Los otros actos salvificos de Yahvé a lo largo de la historia de Israel, como la liberación de la esclavitud en Egipto, son vistos en continuidad con la creación. Por eso mismo, no puede llevarse a cabo de un modo dualista una separación tajante entre el "orden de la creación," en el cual se desarrollaría el drama de la historia profana, y el "orden de la salvación," perfectamente ajeno a los dinamismos historicos (cfr. TL, 201-211). "No hay solución de continuidad entre lo 'natural' y la gracia. Hay una integración profunda y una ordenación hacia la plenitud de todo lo humano en el don gratuito de la autocomunicación de Dios" (TL, 232). En definitiva , Cristo no es un salvador gnóstico ajeno a la carne y a la historia, sino que se ha hecho carne en el Nuevo Testamento dando sentido a toda la creación, como "nueva creación" (cfr. TL, 208ss).

Todo esto lleva a una conclusión teológica fundamental: "No hay dos historias, una profana y otra sagrada, 'yuxtapuestas' o 'estrechamente ligadas,' sino un solo devenir humeno asumido irreversiblemente por Cristo, Señor de la historia. Su obra redentora abarca todas las dimensiones de la existencia y las conduce a su pleno cumplimiento. La historia de la salvación es la entraña misma de la historia humene" (TL, 199). O dicho en otros términos: "No hay dos historias, una de la filiación y otra de la fraternidad, una en la que nos hacemos hijos de Dios y otra en la que nos hacemos hermanos entre nosotros. Eso es lo que el término liberación quiere hacer presente" (FH, 85).

\section{Trangcendencia e historia}

Gutiérrez es consciente de las dificultades que esta afirmación supondria dentro de las categorias de la teologla europea, incluso de la más reciente, pues acabaría conduciendo al viejo dilema formulado más arriba: si se niega el dualismo se destruye la libertad del hombre y la libertad de la gratuidad divina (cfr. TL, 200). Sin embargo, su concepción de la historia lo pone a salvo de esta falsa alternativa. Por una parte, la libertad del hombre queda asegurada $\rightarrow$ pesar de todos 
los condicionamientos - desde el momento en que, como vimos, su praxis es el punto de partida para la conceptuación de lo histórico: no tendría sentido querer contribuir a que los pobres se conviertan en sujetos de su historia si a la vez se concibe la historia como un proceso independiente de todo sujeto humano. Por otro lado, hemos de ver ahora si la gratuidad de la salvación permanece verdaderamente a salvo o si la mencionada praxis histórica y su análisis socioeconómico agota "la convocación cristiana a la esperanza" como pretende algún crítico, no dejando ningún lugar a la trascendencia de la acción salvífica de Dios.

Contra tal sospecha hay que afirmar lo siguiente: la comprension del devenir histórico fuera del determinismo típico de la ilustración deja la historia abierta hacia el futuro y, por tanto, en principio al menos, a la actuación salvadora de Dios. Además, esta apertura al futuro es conceptuada por Gutiérrez desde el motivo neotestamentario del reino escatologico. Por una parte, se afirma que cualquier realización histórica no se puede identificar sin más con el reino de Dios y con la supresión de todos los males (cfr. TL, 67, 308, 351-352), por lo que toda forma de zelotismo, queda excluida (cfr. TL, 299ss). La actividad sociopolítica está siempre relativizada por la esperanza de la venida del reino al final de la historia, pues la liberación en Cristo "conduce esta misma historia más allá de sí misma, a una plenitud que está fuera del alcance de toda previsión y de todo quehacer humano" (FH, 91). Por otra parte, sin embargo, se sostiene que ese reino escatológico está ya presente y actuante "entre nosotros" en los acontecimientos históricos (cfr. TL, 213ss): no basta con apelar al futuro de la parusia, sino que hay que entender ese futuro desde la actualidad histórica de la encarnación: "La muerte y la resurrección de Jesús son nuestro futuro, porque son nuestro presente riesgoso y esperanzado" (TL, 283s).

En este sentido puede decirse con Gutiérrez que la esperanza en cuanto "atracción de 'lo que vendrá' es el motor de la historia. La acción de Yahvé en la historia y su acción al final de la historia son pues inseparables" (TL, 219). Rahner, como vimos, hacía también de la escatología la "entelequia" de la historia. Pero en su esquema, últimamente dual, la "atracción" de Dios no afecta primeramente a la historia entera, también a sus aspectos "categoriales," sino más bien a la subjetividad transcendental, llamada al encuentro definitivo con Dios en la "visión beatífica." Para Gutiérrez, en cambio, que la escatología sea la entelequia de la historia significa que toda la actividad histórica de la humanidad está llamada al cumplimiento definitivo del reino. La perspectiva es más integradora en dos sen- 
tidos: por una parte, todo el hombre, y no una parte del mismo, queda incluido en la escatología; por otra, el tema biblico del reino sustituye al más helénico e individualista de la visio beatifica.

Desde esta perspectiva, la actuación de Dios y el quehacer del hombre no entran necesariamente en conflicto. Dios está presente en el devenir histórico, estimulándonos a ser artífices de esa marcha (cfr. TL, 178, 202, 360). Ciertamente "la palabra es un don gratuito del Señor. Pero el evengelio no es ajeno al proyecto histórico, por el contrario, proyecto humano y don de Dios se implican mutuamente" (TL, 320). Este don de Dios es el fundamento de las posibilidades de la praxis liberadora, la cual, a su vez, hace concreto e historico ese don (cfr. ibid). Como recuerda Gutiérrez, ya la constitución Gaudium et spes presenta al hombre como colaborador de Dios en la creación y en el crecimiento del reino (cfr. 226-232), por más que en ella se propende a limitar el contenido de esa colaboración al dominio científico-técnico de la naturaleza, tendiendo a subestimar la otra dimensión de la praxis histórica: la liberación socio-política (cfr. TL, 232s). ${ }^{37}$ Desde una perspectiva bíblica, la acción auto-liberadora del hombre (salida de Egipto) es, al mismo tiempo, acción salvífica de Dios y "creación" de Israel (cfr. TL, 209-210, 233). Igualmente, la acción de Dios derribando a los poderosos y alzando a los oprimidos (Lc 1, 47ss) es también acción del oprimido mismo, pues en él "el Señor salva la historia" (FH, 72, cfr. TL, 210).

Con esto no peligra en absoluto la transcendencia de Dios ni se reduce a lo analíticamente calculable mediante un análisis socioeconómico. Muy al contrario, el amor preferencial de Dios por los pobres, no porque éstos sean más buenos o tengan más méritos, sino simplemente porque son pobres, es justamente la paradoja que escapa a todo cálculo fariseo y en ella se revela la gratuidad del don de su reino de amor y justicia (cfr. FH, 188). Lo que sucede es que la transcendencia ya no es pensada con categorias duales y estáticas, más típicas del pensamiento griego que del bíblico: la transcendencia no se asegura mediante una distinción metafísica entre lo espiritual y lo temporal, entre lo trascendental y lo categorial, sino en términos más históricos y dinámicos. La Biblia nos presenta un Dios que hace de la humanidad su propio templo, que pone su tienda en medio del pueblo y lo acompaña en el camino hacia su liberación (cfr. TL, 244250), convirtiendo a los pobres y oprimidos en sacramento vivo de su presencia (cfr. TL, 254ss). En virtud de esto, la cuestión de la transcendencia no se plantea en términos de "promesa temporal o promesa espiritual," sino como tension entre las liberaciones parciales y el cumplimiento pleno al fin de la historia (cfr. TL, 223; FH, 236). 
Desde esta perspectiva habria que decir que Dios no es, como ha tendido a pensar la teología clásica, transcendente a la historia, sino transcendente en la historia. ${ }^{39}$ Es decir, el reino de Dios está presente en la historia llevándola hacia su culminación final más allá de sf misma. Dios no está fuera de la historia (Kant), pero tampoco se constituye en ella (Hegel), sino que la historia misma se constituye desde su último fundamento posibilitante de futuro, desde el Dios de Jesús (cfr. TL, 332s).

\section{Conclusión}

La concepción de la historia de Gutiérrez se distancia significativamente de la concepción socio-evolutiva de la ilustración en la medida en que (1) mantiene la praxis humana como el centro de su reflexión sobre la historia, sin entregarla a ningín macro-sujeto; y sobre todo en la medida en que (2) esta praxis es entendida desde el amor preferencial y liberador de Dios por la victimas de la historia. Justamente porque (3) la teología de la liberación es mucho más independiente y crítica frente a los presupuestos ilustrados que la teología europea clásica, (4) Gutiérrez puede situarse más allá de la falsa alternativa entre paralelismo o identidad: solamente hay una historia, la historia profana, a la cual Dios hace historia de la salvación desde las primicias ya presentes del reino.

\section{Notas}

1. Las obras de Gutiérrez se citarán según el siguiente sistema de siglas:

TL: Teología de la liberación. Perspectivas, Salamanca, 1972. 399 pp.

FH: La fuerza histórica de los pobres, Salamanca, 1982, 292 pp.

BPP: Beber en su propio pozo, Salamanca, 1984, 182 pp.

HD: Hablar de Dias desde el sufrimiento del inocente. Una reflexión sobre el libro de Job, Salamanca, 1986, 187 pp.

DO: Dias o el oro en las Indias, siglo XVI, Lima, 1989.

2. Cfr. Joseph Ratzinger, Politik und Erlösung: zum Verhälinis von Glaube, Rationalität und irrationalem in der sogenannten Theologie der Be. freiung. Oppladen, Westdeutschen Verlag, 1986. Véase sobre todo la página 21. Frente a la visión ilustrada de la historia, as! definida, que serfa la propia del libro de Gutiérrez, Ratzinger propone regresar al modelo de Aristóteles, quien, según él, habría subordinado la política no a la metafísica ni a la física, sino a la ética. Una lectura atenta del segundo capítulo del primer libro de la Etica a Nić́maco (1094 a-b) muestra, sin embargo, que para Aristóteles es la ética la que se subordina a la polftica, puesto que la política es para el Estagirita la disciplina que se ocupa del bien superior del hombre: su bienestar colectivo (¡Áristóteles no conoce ningún bien extraterreno!). Por otra 
parto, la dependencia de la política aristotélica respecto a su metafíaica es de todo punto evidente. Una recensión de $M$. Sievernich puede verse en Theologie und Philosophie, 64 (1989), pp. 314-15.

3. Cfr. Andrés Tornos, "Eeperanza e historia," Miscelánea Comillas, Madrid, num. 45 (1987), pp. 13-14. Frente a esta visión "moderna" o iluetrada el autor propone una intereante idea de la historia, caracterizada por la pluralidad e independencia de los procesos, por la ausencia de un único sentido de la historia, de una sola razón universal, etc. No nos ocuparemos en este trabajo directamente del valor que tal aportación puede tener, sino más bien de su critica a Gutiérrez.

4. Seguiremos aqu, parcialmente, la lectura que de la ilustración hace J. Habermas en aus obras Erhenninis und Interesse, Frankfurt, 1968, pp. 14-35; 57-64, 72s; 243s; Technik und Wissenschaft als "Ideologie," Frankfurt, 1968, pp. 9-47; Theorie und Prario, Neuwied/Berlin, 1969 (3a. ed.), pp. 89-107; Kultur und Kritik, Franldurt, 1973, pp. 389-398; Zur Rekonstruktion des historishen Materialismus, Frankfurt, 1976, pp. 9-48; 56-58; 159-162. También puede verse E. M. Ureña, La crítica kantiana de la sociedad y de la religion. Kant, predecesor de Marx y de Freud, Madrid, 1979, pp. 129-151.

5. De Kant pueden verse, sobre todo, sus escritos Uber Pädagogik, contenido de sus lecciones en la unjversidad de Konigsberg en los años 1776-77; cfr. Werkausgabe, Bd. XII, Frankfurt,1977, pp. 693-712. De Hegel puede verse, además de sus Aufsätze aus dem kritischen Journal del Philasophie und andere Shriften ous der jenenser Zeit (Stuttgart, 1927), el libro de G. Lukacs, Der junge Hegel und die Problema der kapitalistischen Gesellschaft, Berlin, 1954. De Marx sus famosos Okonomish-philasophische Manuskripte aus dem Jahre 1844, MEW, Ergkinzungsband, Berlín, 1968, pp. 465-590, y sus Thesen über Feuerbach, MEW, Bd. 3, Berlín 1962, pp. 533-535. Ed. cest. UCA Editores, San Salvador, 1987, 145 pp.

6. Sobre este punto puede verse E. M. Ureña, La teorla crltica de la sociedad de Freud. Represión y liberación, Madrid, 1977, pp. 153-164.

7. Cfr. I. Kant, "Idee zu einer allgemeinen Geschichte in weltbürgerlichen Absicht," en Werkausgabe, Frankfurt, 1968, Band XI, p. 49.

8. Cfr. Ibid., "Kritik der praktischen Vernunft," Werkausgabe (op. cit.), Bd. VII, pp. $219 \mathrm{gs}$.

9. Cfr. Ibid., "Idee zu einer allgemeinen Geschichte..." (op. cit.), pp. 37; 45.

10. Cfr. G. W. F. Hegel, Grundlinien der Philosophie des Rechtes ader Naturrecht und Staatswissenschaft im Grundrisse, Stuttgart, 1928; y, sobre todo, sus Vorlesungen über die Philosophie der Geschichte, Werke, Stuttgart, 1928, pp. 25-134.

11. Cfr. K. Marx, Zur Kritik der Politischen ökonomie, Prólogo (1859), MEW, Bd. XIII, pp. 7-11.

12. Cfr. Ibid., Das Kapital, Bd. I, en NEW, BD. XXIII, pp. 15-16.

13. Una crítica a los presupuestos filosóficos de la concepción ilustrada de la historia puede verse en X. Zubiri, Naturaleza, historia, Dios, Madrid, 
1987 (9a. ed.), pp. 115.135, también en "La dimensión histórica del ser humano," Siete ensayos de antropologla filasbfica, USTA, Bogotá, 1982, S. 117-174.

14. Cfr. J. Habermas, Zur Rekonstruktion des Historischen Materialismus, Frankfurt, 1976, pp. 9-45; 67-88; 167-194.

15. Cfr. ou Theorie des kommunikativen Handelns, Frankfurt, 1987, Bd. 2, p. 260 o sus consideraciones sobre la evolución de la racionalidad misma en la primera parte del primer volumen.

16. La tesig se halla en oug Vorlesungen über die Philosophie der Geschichte (op. cit.). La esclavitud era en aquel tiempo todavfa práctica habitual de los parees "civilizados."

17. Cfr. carta a Kautsky 1882, MEW, 358.

18. Marx mismo saludó asf la tarea colonizadora de los ingleses en la India: "Inglaterra tiene que cumplir una doble mieión en la India, destructora y renovadora: la destrucción del antiguo orden social asiático y la creación de los fundamentos materiales de un orden social occidental en Asia," New York Daily Tribune, 1853, MEW, Bd. 9, p. 221. Vóase también p. 226.

19. La obra misma de Antonio Gramsci es un ejemplo de que incluso de los textos más "duros" del Marx adulto se puede realizar una lectura no determinista. Cfr. sus Quaderni dell carcere, IV vols. Edizione critica dell'Instituto Gramsci. Gjulio Einaudi editore, Turin, 1975. Sobre todo su "Introduzione allo Studio della filosofia," vol, II, pp. 1363-1509.

20. Véase, por ejemplo, K. Loewith, "Mensch und Geschichte" en sus Gesammelte Abhandlungen zur Kritik der geschichtlichen Existenz, Stuttgart, 1969 (2a. ed.), pp. 152-178; "Philosophische Weltgeschicht?," en Aufsätze und Vorträge 1930-1970, Stuttgart, 1971, pp. 229-256.

21. Cfr. A Harnack, Das Wesen des Christentums, München, 1964, citado en J. Sobrino, Cristologta desde América Latina (esbazo a partir del seguimiento del Jesús histórico), México, 1976, p .65.

22. Cfr. O. Culmann, Heil als Geschichte, Tubingen, 1965, pp. 58-59, 135.

23. Cfr. W. Pannenberg, "Welgeschichte und Heilsgeschichte," en Probleme biblischer Theologie (G. von Rad zum 70. Geburtstag), Munich, 1971, pp. 340-366.

24. Sobre eate punto, pueden verse las criticas de Sobrino en su Cristologia..., op. cit., pp. 31-34.

25. Cfr. su "Historia de las Indias," en Obras escogidas II, p. 511. Citado en FH, 253. Véase también DO, 168 ss.

26. Las obras de Rahner serán citadas aqur de acuerdo al siguiente sistema de aiglas:

BO: "Bermerkungen zum Begriff der Offenberung," en K. RahnerJ. Ratzinger, Offenbarung und Uberlieferung, Questiones Disputatae, 25, Herder, Freiburg, 1965.

GG: Grundkurs des Glaubens. Einfuihrung in den Befgriff des Christentums, Herder, Freiburg, 1976.

NCR: "Ober die Heilebedeutung der nichtchristlichen Religionen," en 
Schriften zur Theologie, Bd. 13., 1978, 8. 341-350.

NG: "Uber das Verhaltnis von Natur und Gnade," en Schriften zur Theologie, Bd. 1., 1954, S. 323-346.

NL: "Uber die Einheit von Nachten- und Gottesliebe," Schriften zur Theologie, Bd. 6, 1965, S. 277.298.

PH: "Profangeschichte und Heilsgeschichte," Schriften zur Theologie, Bd. 15, 1983, S. 11-23.

WH: "Weltgeachichte und Heilegeschichte," Schriften zur Theologie, Bd. 5., 1962, S. 115-135.

27. Cfr. E. Schillebeeckx, Cristo y los cristianos. Gracia y liberación, Madrid, 1982, pp. 517-519; I. Ellacuŕra, "Historicidad de la salvación cristiana," en la Revista Latinoamericana de Teologia, San Salvador, enero-abril 1984, num. 1, pp. 5-45.

28. Cfr. X. Zubiri, Inteligencia sentiente, vol 1: Inteligencia y realidad, Madrid, 1984, pp. 113-132.

29. Cfr. J. Sobrino, "Los 'signos de los tiempos' en la toologia de la liberación," Estudios eclesiásticos, vol. 64 (1989), pp. 249-269.

30. Gramsci toma como modelo para eu teorfa de los intelectuales orgánicos la habilidad que la Iglesia católica ha tenido tradicionalmente para mantener a los intelectuales unidos al pueblo (cfr. Quaderni 11, op. cit., pp. 1380-1381). La diferencia consiste en que, según él, esta unión tenía solamente el fin de mantener al pueblo en su ignorancia y no de liberarlo. Cuando se critica el uso de la expresión "intelectual orgánico" por Gutiérrez convendrfa no olvidar su origen.

31. Tal como decfa Monseñor Romero en su discurso de Lovaina. Sobre este punto puede verse I. Ellacurfa, "El pueblo crucificado," en Conversión de La Iglesia al reino de Dios para anunciarlo y realizarlo en la historia, Santander, 1984, pp. 25-64.

32. Esta es, al menos, la esperanza que Gutiérrez formula. En este punto quizás le pudiera achacar a sus primeros escritos un optimismo tal vez exagerado, pero de ningrín modo un determinismo, como vamos a ver.

33. En un plano filosófico, Gutiérrez recurre con frecuencia a una interpretación de Marx en términos de "Glosofia de la praxis," lo que manifiesta probablemente una cierta influencia de la filosofía de Gramsci y de otros sectores criticos del marxiemo occidental y latinoamericano. Por desgracia no pone suficientemente de manifiesto, por una parte, la ruptura que este modo de pensar entraña respecto a Kant y a Hegel; y, por otra parte, el problema de la "recarda" del marxismo oficial en una interpretación determinista y objetivista de la historia, en cuyas antipodas desde luego se halla Gutiérrez.

34. Cfr. Sollicitudo rei socialis, 14.

35. Cfr. I. Ellacuria, "El pueblo crucificado," op.cit.

36. Gutiérrez cita aqư Populorum Progressio, 21. Véase también Euangelii Nuntiandi, 31.

37. Curiosamente, ésta es también la crítica de Habermas a Marx: éste 
habría concebido el progreso hietórico, al menos en ous formulaciones categoriales, preponderantemente en términos de desarrollo técnico de las fuerzas productivas, relegando a eegundo término la pravis social y politica, cfr. J. Habermas, Tehnik und Wiseenschaft als 'Ideologie,' op. cit., pp. 458s; Erkenntnis und Interesse, op. cit., pp. 57-60. También puede verse E. M. Ureña, La teorla critica de la sociedad de Habermas. La crisis de la sociedad industrializada, Madrid, 1978, pp. 36-39.

38. Sobre este punto serfa iluminador tener en cuenta la concepción do la tranecendencia de X. Zubiri, El hombre y Dios, Madrid, 1988 (4a. ed.), pp. 174, 202-204, 308-311, 377-379, etc. 